\title{
Comprehensive tobacco control policies and the smoking behaviour of Canadian adults
}

\author{
Thomas Stephens, Linda L Pederson, John J Koval, Jennifer Macnab
}

Ontario Tobacco

Research Unit/Thomas

Stephens \& Associates,

Manotick, Ontario,

Canada

T Stephens

CDC/NCCDPDHP,

Office on Smoking and

Health, Atlanta,

Georgia, USA

L L Pederson

Department of

Epidemiology and

Biostatistics,

University of Western

Ontario, London,

Ontario, Canada

J J Koval

J Macnab

Correspondence to:

Dr Thomas Stephens,

Ontario Tobacco Research

Unit/Thomas Stephens \&

Associates, 1118 John Street,

Box 837, Manotick, Ontario

Canada K4M 1A7

tstephens@cyberus.ca

Received 1 October 2000

and in revised form

4 July 2001 .

Accepted 9 July 2001.

\begin{abstract}
Objective-To examine the associations of cigarette prices, restrictions on public smoking, and health education with the odds of adult smoking and amount smoked daily.

Design-Multi-level analysis of adult (age 25+) smoking patterns in Canada's National Population Health Survey, after adding administrative data on prices, bylaws, and health education according to the survey respondent's place of residence.

Setting/subjects-Population based sample of Canadians age $25+$ in households (n = 14 355).
\end{abstract}

Outcome measures-Smoking status, amount consumed daily.

Analysis-Logistic regression for smoking status, multiple regression for amount smoked, with controls for age, education, marital status; separate analyses for men and women.

Results-Cigarette prices were positively associated with the odds of being a non-smoker and negatively with amount smoked, for adults of both sexes. Per capita health education expenditures were positively associated with the odds of being a non-smoker and negatively with amount smoked-for men but not women. The restrictiveness of municipal bylaws limiting public smoking was positively associated with the odds of being a non-smoker and negatively with amount smoked-for women but not men. These results are independent of age, education, and marital status.

Conclusions-To be effective, tobacco control must comprise a mix of strategies as men and women respond differently to health education and restrictions on public smoking; taxation, reflected in higher cigarette prices, is the only one of these measures related to smoking for both sexes. This model permits calculations of the level of increase in each measure that is required to reduce the prevalence of smoking by a specified amount.

(Tobacco Control 2001;10:317-322)

Keywords: bylaws; education; policy; taxes

Comprehensive policies to curb cigarette smoking generally employ some mix of taxation, education, and legislation/regulation in order to encourage prevention of smoking, cessation, and protection from environmental tobacco smoke for non-smokers. ${ }^{1-4}$ While the value of specific policies, particularly taxation, has long been understood, ${ }^{1-3}{ }^{5-7}$ the relative and independent contribution of these common policy measures to tobacco control is not well delineated, particularly for adults. Moreover, the policy effects on different population subgroups are generally unknown. This paucity of information arises from both substantive and methodological issues.

Conclusive analysis of tobacco control policies is complicated by the fact that the policy measures exist at a variety of aggregate levels (federal, state/province, municipal, worksite etc), while other factors known to be associated with smoking-notably age, sex, education, and other smokers in the household ${ }^{1-3-10}$ - are individual level variables. Since data on both individual characteristics and the policy context are not normally available from the same source, analyses of the impact of price or regulation, for example, typically use an ecological or econometric approach. ${ }^{11-13}$ Unfortunately, this approach cannot readily account for individual differences. This has led to calls for the development of designs and analytical approaches to overcome this critical limitation. ${ }^{14} 15$

Firstly, smoking policy studies that involve comparisons among jurisdictions have typically examined only one or two policies at a time. Taxation (or, more accurately, price) has been the most frequently studied policy, either on its own $^{67141617}$ or in combination with clean air bylaws. ${ }^{11}{ }^{12}{ }^{18-20}$ On its own, taxation in the form of price increases appears to have more of an impact on young smokers than on established ones, and may affect both amount smoked and prevalence. ${ }^{6}{ }^{70-23}$

Secondly, complex policies have often been reduced to a single numerical score in these studies. Most commonly, clean air bylaws are defined as simply present or absent across a range of settings. ${ }^{11}{ }^{12} 18-20$ Of those studies examining multiple policies, only one has identified distinct locales for restricted smoking, ${ }^{24}$ and none has included other regulatory measures such as enforcement or signage requirements.

Finally, most of these policy studies focus on a single outcome variable, typically smoking status, ${ }^{111825}$ amount smoked ${ }^{19}$ or per capita sales. ${ }^{14} 1725$ Relatively few have examined both smoking status and amount smoked. ${ }^{13} 162021$

Few studies have examined two or more policies simultaneously while controlling for individual characteristics, and these have their own limitations. Chaloupka and colleagues ${ }^{20} 21$ have studied the association of price, clean air ordinances (bylaws), and purchasing restrictions on smoking by high school and college 
Table 1 Policy variables used in this analysis (unweighted values)

\begin{tabular}{lllll}
\hline Variable (units or possible range) & Mean & $\begin{array}{l}\text { Standard } \\
\text { deviation }\end{array}$ & Minimum & Maximum \\
\hline Price, 200 cigarettes (\$C) & $\$ 30.28$ & $\$ 9.75$ & $\$ 21.28$ & $\$ 50.62$ \\
Public education expenditure/capita (\$C) & $\$ 0.36$ & $\$ 0.54$ & $\$ 0.01$ & $\$ 1.87$ \\
Clean-air bylaw restrictions (0-24) & 5.3 & 4.7 & 0 & 16 \\
Provisions for enforcing bylaws (0-2) & 0.6 & 0.6 & 0 & 2 \\
Bylaw signage requirements (0-2) & 0.2 & 0.5 & 0 & 2 \\
\hline
\end{tabular}

students. Stephens and associates examined the association of both price and clean air regulation on smoking in a national population, ${ }^{18}$ but smoking status was the only outcome variable and only a rough indicator was used for the regulations. Townsend and colleagues ${ }^{13}$ attempted to examine the association of prices and health education, but "health publicity" as an indicator of health education was not clearly defined and lacked appropriate quantification.

This study is therefore intended to answer the following questions about tobacco control: (1) What are the separate and joint associations of cigarette prices, restrictions on smoking in public places, and health education with (a) the likelihood of adult smoking, and (b) the amount smoked by adults?

(2) Are there subpopulations in which these policies have more apparent effect than in others? In particular, are the associations between policy and smoking the same for men and women?

\section{Methods}

OUTCOME MEASURES AND CONTROL VARIABLES

The outcome measures for adults were (a) smoking status (current smoker/non-smoker), and (b) amount smoked by daily smokers. "Current" smoker refers to both daily and non-daily smokers.

The individual level variables that were controlled for in the sex specific analyses were: age, education completed, and marital status.

Both outcome and control variables were taken from the cross sectional data of the public use data file of the National Population Health Survey (NPHS), conducted by Statistics Canada in 1994-95 on a nationally representative household based sample of 17626 Canadians age 12 years and older. ${ }^{26}$ (The NPHS is Canada's equivalent of the US Health Interview Survey.) Data in this study were for 14355 persons age 25 years and older. Using a standard set of questions on smoking (and other health behaviours and issues), interviewers completed in-home computer assisted data collection in June, August, and November 1994, and March 1995. Data of interest to this study were collected from one individual per household age 12 years or older, who was selected at random (although we analysed data for adults only in this case). Proxy data (from a third party) were accepted only in the case of illness or incapacity on the part of the selected interviewee; this amounted to only $4 \%$ of cases.

MEASURES OF TOBACCO CONTROL POLICIES The independent variables in this study are:
- the price of cigarettes and recent price changes

- public tobacco control/health education expenditures

- municipal bylaws limiting smoking in public places

- provisions for enforcement of the bylaws

- requirements for posting signs about smoking bans.

These variables were taken from three distinct data sources, described below, and added to the NPHS data file according to respondent's place of residence. All are from sources overlapping the 12 month data collection period of the NPHS. Table 1 summarises these variables.

\section{Price of cigarettes}

The retail price of cigarettes (and other commodities) in 26 major Canadian cities is monitored regularly by Statistics Canada. For current price, we used the value for July 1994 for a carton of 200 cigarettes. ${ }^{27}$ The retail price reflects the dealers' cost, profit, and federal and provincial taxes. We used municipality specific values for all the major cities in Canada and provincial averages for other locations within the same province (within-province variation is much smaller than inter-province variation in price). It should be noted that the federal government and five provincial governments reduced their excise taxes on cigarettes in February 1994, just before the period under study. These tax cuts effectively reduced cigarette prices by $50 \%$ for about two thirds of the Canadian population. After the initial reduction in February, prices were stable for the balance of the survey data collection period.

Public tobacco control expenditures

In Canada, the provinces play a major role in the delivery of tobacco control programmes, primarily in the form of health education and bylaw enforcement. In order to quantify this role, which varies substantially from province to province and over time, we used dollar figures for expenditures during the fiscal year April 1994 through March 1995 collected from each of the 10 provincial health departments. ${ }^{28}$ Population estimates from the 1991 Census of Canada were used to calculate per capita expenditures.

\section{Municipal bylaws}

A federal government survey provided a detailed description of restrictions on public smoking in place in $1995 .^{29}$ We rated 367 bylaws for restrictiveness, as follows: with codes similar to those in a Centers for Disease Control and Prevention (CDC) study of state laws, ${ }^{30}$ we scored bylaw strength $0-2$ for each of 12 locations within the municipality $(0=$ no limits on smoking; $1=$ designated smoking areas required or allowed; $2=100 \%$ smoke-free); restrictiveness was the sum of location specific scores. The 30 municipalities that did not respond to the survey were scored as zero in restrictiveness; the vast majority of these were small communities, which are less 
likely to have any restrictions on public smoking. ${ }^{31}$

\section{Municipal signage requirements}

Signs may heighten a bylaw's effectiveness by increasing its visibility. Our scoring scheme gave points for measures that raise the likelihood of self enforcement, which is relied upon in a wide variety of settings. ${ }^{32}$ Scores are based on municipality specific descriptions of signage regulations and were scored $0-2$, by awarding one point for requiring both symbols and words on signs and one point for requiring a sign at the entrance of public buildings with restrictions. The average score was low, as 297 municipalities out of 367 had no provision for signage. This variable was treated as binary (signs required/not required) in the analyses.

Enforcement of clean air bylaws

While self regulation of public smoking is important for compliance, it is seldom adequate. Official enforcement is thus fundamental for bylaw effectiveness. ${ }^{23}$ In the absence of data on actual enforcement effort, we scored the provisions for enforcement contained in each bylaw, again using data specific to each municipality, allocating $0-2$ points as follows: one point for having a designated enforcement official, and one point for fines that escalate with repeated offenses. Since 193 of 367 municipalities had no provisions for enforcement and there was little variation among the remainder, we treated this variable as binary in the analyses.

LINKAGE OF DATA SETS

Data on these five tobacco control policies were added to every survey record in the NPHS data file, using detailed geographic codes for the municipal level data (prices and bylaws). Since these were not available on the public use file, the linkage was carried out by Statistics Canada on their master file. Per capita tobacco control expenditures were added to the survey file using the respondent's province of residence.

ANALYSIS

After linking the policy variables to the survey file, $8615(49 \%)$ of the survey cases had no bylaw data - that is, these respondents lived in areas for which the bylaw study provided no data. Because the coverage of the bylaw study had been extensive, we suspected that these cases of missing data were from communities with no bylaws. To confirm this, we contacted a random sample of 40 of these communities,

Table 2 Multivariate odds of being a non-smoker associated with various tobacco control policies, Canada, age 25+

\begin{tabular}{lllllllll}
\hline & \multicolumn{3}{l}{ Men } & & & \multicolumn{2}{l}{ Women } \\
\cline { 2 - 3 } & $\begin{array}{l}\text { Odds } \\
\text { ratio }\end{array}$ & $95 \%$ CI & p Value & $\begin{array}{l}\text { Odds } \\
\text { ratio }\end{array}$ & $95 \%$ CI & p Value \\
\hline Price of cigarettes & 1.02 & 1.00 to 1.03 & 0.01 & & 1.01 & 1.00 to 1.02 & 0.05 \\
Public education expenditure & 1.36 & 1.09 to 1.70 & 0.01 & & 1.13 & 0.91 to 1.39 & $\mathrm{NS}$ \\
Clean air bylaw restrictions & 0.99 & 0.97 to 1.01 & $\mathrm{NS}$ & & 1.02 & 1.00 to 1.04 & 0.03 \\
Provisions for enforcing bylaw & 1.21 & 1.00 to 1.46 & 0.05 & & 0.99 & 0.83 to 1.19 & $\mathrm{NS}$ \\
Bylaw signage requirements & 1.25 & 1.01 to 1.55 & 0.04 & & 0.87 & 0.70 to 1.08 & $\mathrm{NS}$ \\
\hline
\end{tabular}

CI, confidence interval; NS, not significant stratified by size and region, to ascertain their 1995 bylaw status. Thirty two of them $(80 \%)$ confirmed that they had no clean air bylaws as of mid 1995. Accepting that there would be some misclassification on this variable, we imputed "no restrictions/enforcement/ signage" for all survey cases missing bylaw data, thereby increasing the total usable sample for the analyses to 14355 cases age 25 years and older. Since the survey oversampled residents of small municipalities and rural areas, the cases with imputed data were in fact far fewer than $49 \%$ of the weighted sample used in analysis.

Logistic regression was used to model smoking status (current/not) and multiple linear regression to model amount smoked. Age, education (no high school/high school completed/post-secondary), and marital status (married/not married) were controlled in the regressions, which were conducted separately for men and women. As the distribution of expenditures per capita was highly skewed, we used the square root of this value in the regressions. Enforcement provisions and signage were treated as binary variables (some/none), while the scores for price and bylaw restrictiveness were entered into the model as described above. Because of the complex sample design underlying the survey, we calculated exact variances using the bootstrap method. ${ }^{33}$ There was no collinearity among the policy variables.

\section{Results}

SMOKING STATUS

We found significant associations between each of these tobacco control policies and the odds of being a non-smoker-while controlling for individual differences and the other policies. The associations were all in the expected directions but were often different for men and women.

Tobacco taxation (price) was positively related to the odds of being a non-smoker for both sexes - that is, as price increases, the odds of an individual being a non-smoker also increase. This was the only policy to have the same association for both men and women, although it was stronger for men (table 2). The price elasticity for type of smoker for men is thus -0.5 (based on a $30.4 \%$ decrease in odds of being a smoker associated with $63 \%$ price increase), and for women it is $-0.3(30.4 / 102)$.

Tobacco control expenditure per capita was positively related to the odds of being a non-smoker for men, but not for women. In contrast, the restrictiveness (severity and extent) of municipal bylaws limiting public smoking was positively related to the odds of being a non-smoker for women, but not for men. Interestingly, however, requiring prominent signs to inform the public of the non-smoking bylaw and having written provisions for enforcement (designating an enforcement authority, escalating fines for repeat offences) were both significantly related to the odds of being a non-smoker for men, but not for women. 
Table 3 Amount smoked daily associated with various tobacco control policies, Canada, daily smokers age 25+, 1996-97

\begin{tabular}{|c|c|c|c|c|c|c|}
\hline & \multicolumn{3}{|l|}{ Men } & \multicolumn{3}{|l|}{ Women } \\
\hline & $\begin{array}{l}\text { Estimate } \\
\text { (No.cigs) }\end{array}$ & $95 \% C I$ & p Value & $\begin{array}{l}\text { Estimate } \\
\text { (No. cigs) }\end{array}$ & $95 \% C I$ & $p$ Value \\
\hline Tax cut in Feb 1994 & 12.4 & 0.8 to 24.0 & 0.01 & 9.3 & -0.7 to 19.3 & 0.05 \\
\hline Current price of cigarettes & 0.1 & -0.9 to 0.3 & NS & 0.1 & -0.1 to 0.3 & NS \\
\hline \multicolumn{7}{|l|}{ Interaction: current price $x$} \\
\hline tax cut in February 1994 & -0.3 & -0.6 to -0.0 & 0.02 & -0.2 & -0.5 to 0.0 & 0.07 \\
\hline Public education expenditure & -2.7 & -4.6 to -0.8 & $<0.001$ & -0.9 & -0.1 to 0.3 & NS \\
\hline Clean air bylaw restrictions & -0.1 & -0.2 to 0.1 & NS & -0.1 & -0.3 to 0.1 & 0.05 \\
\hline Provisions for enforcing bylaw & -0.3 & -1.6 to 1.0 & NS & 0.7 & -0.8 to 2.2 & NS \\
\hline Bylaw signage requirements & 0.0 & -1.9 to 2.0 & NS & 0.6 & -1.4 to 2.5 & NS \\
\hline
\end{tabular}

AMOUNT SMOKED DAILY

The associations between these policies and the amount smoked by daily smokers (table 3) were similar to those just described for smoking status. The substantial tax cut in February 1994, affecting about two thirds of the population, was significantly related to the amount smoked by both men and women - that is, the larger the drop, the more the amount smoked, from 9.3 to 12.4 cigarettes more for women and men, respectively.

While there was no direct association between the current price of cigarettes and amount smoked, there was an interaction of the tax cut and current price of cigarettes. In the five provinces that experienced a recent tobacco tax cut (but still retained some variation in price), there was a negative association between price and amount smoked by male daily smokers. There was a similar tendency for women.

In a fashion similar to the association with smoking status, health education expenditures were significantly inversely related to the amount smoked by men, but not women, while the restrictiveness of bylaws was significantly inversely related to the amount smoked by women, but not men. Neither bylaw sign requirements nor enforcement provisions were related to the amount smoked daily by men or women smokers.

\section{Discussion}

This study set out to assess the associations of cigarette prices, restrictions on smoking in public places, and health education on (a) the likelihood of adult smoking, and (b) amount smoked daily. Our findings demonstrate significant independent associations for each of these policy measures, after controlling for sex, age, education level, and marital status. Moreover, these policy interventions tend to have an association with smoking status that is similar to its association with amount smoked. However, these associations are sometimes different for men and women. They may be summarised as follows:

- as the price of cigarettes increases, the odds of being a smoker decline; this is true for both men and women, but more so for men

- in the Canadian provinces that reduced tobacco taxes in 1994, the amount smoked by men and women smokers is much greater than in the provinces that maintained taxes; further, within the tax cut provinces, there is a negative association between current price and amount smoked

- as tobacco control expenditures increase, the odds of not smoking increase for men, but not women, and the average amount smoked by men, but not women, declines

- with increasing restrictions on smoking in public places, the odds of being a non-smoker increase for women but not men, while the amount smoked daily declines

- where there are the provisions for bylaw enforcement, the odds of being a non-smoker also increase for men, but not women; there is no association with amount smoked for either sex

- similarly, as the visibility of a no-smoking bylaw increases through prominent signage, the odds of being a non-smoker increase for men, but not women; there is no association with amount smoked for either sex.

These associations are consistent with previous studies showing the positive contribution of tobacco taxes and clean-air bylaws to tobacco control ${ }^{1367111216-182021}$ and the greater price sensitivity of men than women. ${ }^{3}$ Although there is much less literature on the sex specific effects of smoking restrictions, our finding that women's smoking is more strongly associated than men's with the existence of clean air laws is consistent with results from the Massachusetts Tobacco Survey ${ }^{3}$ but inconsistent with an earlier study by Chaloupka. ${ }^{34}$ The sex specific effects of clean air restrictions and public education both need further study.

The contributions made by this study are: (a) demonstrating the independent and comparative effects of these three major tobacco-control policies, and (b) quantifying the contribution of public health education and demonstrating its sex specific effects, while (c) controlling for individual differences that are usually overlooked in comparing tobacco control in different jurisdictions.

There are two fundamental implications of these findings for tobacco control:

(1) since price (or taxation) is the only policy associated with the smoking behaviour of both men and women, after controlling for age, education, and marital status, it should be an integral part of any serious, comprehensive tobacco control policy

(2) since health education and clean air bylaws are associated with the smoking behaviour of adults differently according to sex, both should be part of comprehensive tobacco control policy in order to reach the entire population.

Having established the independent odds ratios for being a smoker in the face of these three basic tobacco control measures, it is theoretically possible to specify how smoking prevalence might change in response to a given change in policy. For example, prevalence should drop from $25 \%$ to $23 \%$ among adult men in Canada if tobacco prices are raised $21 \%$, or by $\$ \mathrm{C} 0.60$ over the $1994-95$ baseline level (table 4). To achieve this same gain among women, however, prices would have to be raised $69 \%$. To reach a prevalence level of 
Table 4 Theoretical policy changes required to achieve specified reductions in the prevalence of smoking, by sex, adults age $25+$, Canada

\begin{tabular}{|c|c|c|c|c|}
\hline & \multicolumn{4}{|c|}{ To reduce prevalence from $25 \%$ to: } \\
\hline & \multicolumn{2}{|l|}{$23 \%$} & \multicolumn{2}{|l|}{$20 \%$} \\
\hline & Men & Women & Men & Women \\
\hline Target for not smoking (\%) & 77 & 77 & 80 & 80 \\
\hline Target odds, not smoking $(\mathrm{p} / 1-\mathrm{p})$ & 3.3 & 3.3 & 4 & 4 \\
\hline Base odds, not smoking $(\mathrm{p} / 1-\mathrm{p})$ & 3 & 3 & 3 & 3 \\
\hline$\%$ increase in odds required & 10 & 10 & 33.3 & 33.3 \\
\hline \multicolumn{5}{|l|}{ Change policies as follows: } \\
\hline Increase price $(\%)$ & 21 & 33 & 69 & 111 \\
\hline i.e. add $\$ /$ pack & $\$ 0.60$ & $\$ 0.98$ & $\$ 2.01$ & $\$ 3.26$ \\
\hline \multirow{2}{*}{$\begin{array}{l}\text { Or increase education spending (\%) } \\
\text { i.e. add } \$ / \text { capita }\end{array}$} & 34.6 & $?$ & 115.3 & ? \\
\hline & $\$ 0.30$ & & $\$ 1.00$ & \\
\hline \multirow{2}{*}{$\begin{array}{l}\text { Or ... upgrade restrictions to bans (\%) } \\
\text { i.e. number of changed locations }\end{array}$} & ? & 73 & ? & 244 \\
\hline & & 4.3 & & 14.5 \\
\hline
\end{tabular}

? = impact unclear, according to the model.

$20 \%$ would require price increases of $33 \%$ for men and $111 \%$ for women.

While such increases over a short period may prove politically impractical, they are not the only effective measure available. A prevalence level of $23 \%$ among men should be achieved by increasing health education spending by $35 \%$, while increasing restrictions on public smoking by $73 \%$ should have a similar effect on women, according to our model (table 4). Alternatively, some combination of policy enhancements could be enacted, bearing in mind that the effects are different for the two sexes.

This study illustrates the value of multi-level analysis in epidemiology ${ }^{35}$ and has added to the body of knowledge in assessing the associations of three tobacco control policies with smoking patterns in a general population. However, refinements are needed. These should include a more detailed and precise measure of health education, quantifying type of activity as well as per capita expenditure, and accounting for actual enforcement of clean air bylaws and not just provisions for it. Even more basically, it would be important to minimise the imputation of any policy variables.

In the current study, the proportion of cases for which "no bylaw" had to be imputed may have reduced the apparent association with smoking. To assess this possibility, we repeated the analyses with only those cases that had no missing bylaw data. The result was very little change in the values of the odds ratios or multiple regressions, but fewer of the associations were significant because of the smaller sample size. The fact that the relationships remained relatively constant despite a substantial reduction in the sample size indicates the robustness of the findings. We opted to report data based on the larger sample with the imputed data.

Even without our data problems, however, this approach to analysis must make some assumptions about the policy context in which the individual lives. For example, our analysis assumes the smoker always purchases cigarettes in his or her own province and that the clean air bylaws in the municipality where one works are not substantially different from those where one lives. Few population based surveys or other data sources are likely to have the level of detail required to avoid these assumptions, and even with them, we have

\section{What this paper adds}

Comprehensive tobacco control policies usually consist of some mix of taxation, education, and legislation/regulation. The value of specific policies, particularly taxation and clean indoor laws, is well documented, but the relative and independent contribution of these common policy measures to tobacco control is not well delineated, particularly for adults. Moreover, with the exception of taxation, the policy effects on different population subgroups are also largely unknown.

This study demonstrates the independent and comparative effects of these three major tobacco control policies, and quantifies the contribution of public health education and demonstrates its sex specific effects, while controlling for individual differences that are usually overlooked in comparing tobacco control in different jurisdictions. Since price (taxation), clean air bylaws, and health are differentially associated with the smoking behaviour of adults according to sex, all three should be part of comprehensive tobacco control policy.

found evidence of the potential impact of all three tobacco control measures. Further study is needed to establish whether the sex differences reported here are reliable, and, if so, what the reasons might be.

Replications and extensions of this study should include other populations, especially youth, using more recent data, from jurisdictions where the changes are not confounded by an abrupt change in tobacco taxation, as was the case in Canada in 1994. Sample size will be important, and it would be very desirable to avoid the extent of imputation of bylaw data that characterised this study. Further, the additional power of a longitudinal design to detect change in response to policy would be a welcome improvement over the cross sectional data used in this analysis. Longitudinal data have been used to good effect by Tauras and Chaloupka in studies of youth smoking. ${ }^{36}$ Nevertheless, this study has clearly shown the importance of taxation, restrictions on public smoking, and health education as three pillars of comprehensive tobacco control policy among adults.

This study was supported by the Robert Wood Johnson Substance Abuse Policy Research Program (Grant No. 033026). Statistics Canada provided the data linkage, Larry Stitt assisted with data analysis; Terry Pechacek of CDC and anonymous reviewers provided many constructive suggestions.

1 US Department of Health and Human Services. Reducing tobacco use. A report of the Surgeon General. Rockville, Maryland: Public Health Service, Office on Smoking and Health, 2000.

2 US Department of Health and Human Services. Reducing the health consequences of smoking: 25 years of progress. A report of the Surgeon General, 1989. Rockville, Maryland: Public Health Service, Centers for Disease Control, Office on Smoking and Health, 1989. (DHHS Publication No (CDC) 89-8411.)

3 US Department of Health and Human Services. Women and smoking. A report of the Surgeon General. Rockville, Maryland: Public Health Service, Office on Smoking and Health, 2001 .

4 World Health Organization. Tobacco-free Europe: action plan. Copenhagen: WHO Regional Office for Europe, 1993. 
5 US Department of Health and Human Services. Major local tobacco control ordinances in the United States. Smoking and Tobacco Control Monograph No 3. Bethesda, Maryland: Public Health Service, National Institutes of Health, 1993. (NIH Publicat

6 Warner KE. Smoking and health implications of a change in the Federal Cigarette Excise Tax. FAMA 1986;255:102832 .

7 Warner KE, Chaloupka FJ, Cook PJ, et al. Criteria for determining an optimal cigarette tax: the economist's perspective. Tobacco Control 1995;4:380-6.

8 Pederson LL. Smoking. In: Stephens T, Graham DF, eds. Health Canada. Canada's health promotion survey 1990: technical report. Ottawa: Minister of Supply and Services Canada, 1993.

9 Pierce JP, Fiore MC, Novotny TE, et al. Trends in cigarette smoking in the United States: projections to the Year 2000. FAMA 1989;261:61-5.

10 Stephens T, Morin M. Introduction. In: Stephens T, Morin $M$, eds. Health Canada. Canada's youth smoking survey: technical report. Ottawa: Minister of Supply and Services technical report.

11 Emont SL, Choi WS, Novotny TE, et al. Clean indoor air legislation, taxation and smoking behavior in the United States: an ecological analysis. Tobacco Control 1992;2:1317.

12 Peterson DE, Zeger SL, Remington PL, et al. The effect of state cigarette tax increases on cigarette sales, 1955 to 1988. Am f Public Health 1992;82:94-6.

13 Townsend J, Roderick P, Cooper J. Cigarette smoking by socioeconomic group, sex, and age: effects of price, income, and health publicity. BMF 1994;309:923-7.

14 Mummery WK, Hagen LC. Tobacco pricing, taxation, consumption and revenue: Alberta 1985-1995. Can f Public Health 1996;87:314-6.

15 Wasserman J. How effective are excise tax increases in reducing cigarette smoking? [editorial]. Am f Pub Health reducing cigarette

16 Hamilton VH, Levinton C, St-Pierre Y, et al. The effect of tobacco tax cuts on cigarette smoking in Canada. Can Med Assoc f 1997;156:187-91.

17 Kaiserman MJ, Rogers B. Tobacco consumption declining faster in Canada than in the US. Am f Pub Health

18 Stephens T, Pederson LL, Koval JJ, et al. The relationship of cigarette prices and smoke-free bylaws to the prevalence of smoking in Canada. Am F Public Health 1997;87:1519-21.

19 Wasserman J, Manning WG, Newhouse JP, et al. The effects of excise taxes and regulations on cigarette smoking. $\mathcal{F}$ Health Econ 1991;10:43-64

20 Chaloupka FJ, Wechsler H. Price, tobacco control policies and smoking among young adults. Working Paper No. 5012, National Bureau of Economic Research, February 1995.
21 Ross H, Chaloupka FJ. The effect of public policies and prices on youth smoking. Research paper series No. 8, ImpacTeen, February 2001 .

22 Ferrence RG, Garcia JM, Sykora K, et al. Effects of pricing on cigarette use among teenagers and adults in Canada 1980-1989. Toronto: Addiction Research Foundation, 1991

23 Larson MJ, Buckley JC, Elliott EA. Data collections on key indicators for policy: alcohol, illicit drugs, and tobacco. Princeton, New Jersey: Robert Wood Johnson Foundation, 1995.

24 Rigotti NA, Pashos CL. No-smoking laws in the United States: an analysis of state and city actions to limit smoking in public places and workplaces. $\mathscr{f} A M A 1991 ; 266: 3162-7$.

25 Breslow L, Johnson M. California's Proposition 99 on tobacco, and its impact. Annu Rev Public Health 1993; 14:585-604.

26 Statistics Canada. National Population health survey public use microdata files. Ottawa, September 1995

27 Statistics Canada. Consumer prices and price indexes, April-June 1994, July-September 1994, OctoberDecember 1994. Catalogue No. 62-101 (quarterly).

28 Cunningham R. Evaluation of federal and provincial legislation to control tobacco, 1994. Ottawa: Canadian Cancer Society, 1995.

29 Health Canada. Smoking by-laws in Canada 1995. Ottawa: Office of Tobacco Control, Health Protection Branch, Health Canada, 1995.

30 Shelton DM, Alciati MH, Chang MM, et al. State laws on tobacco control-United States, 1995. MMWR Morb tobacco control-United States,

31 Asbridge M, O'Grady B, Abernathy T. Municipal antismoking laws in Ontario: a review of legislation to protect the health of non-smokers. Toronto: Ontario Tobacco Research Unit Working Paper Series, 1997.

32 Goss Gilroy Inc and Thomas Stephens \& Associates. Study of smoking policies in various settings in Canada. Report Prepared for the Health Promotion Directorate, Health Canada. Ottawa: August 1995.

33 Yeo D, Mantel H, Liu T-P. Bootstrap variance estimation for the national population health survey. Proceedings of the 1999 annual meeting of the American Statistical Association,

34 Chaloupka F. Clean indoor air laws, addiction and cigarette smoking. Applied Economics 1992;24:193-205.

35 Diez-Roux AV. Bringing context back into epidemiology: variables and fallacies in multilevel analysis. Am F Public Health 1998;88:216-22.

36 Tauras JA, Chaloupka FJ. Price, clean indoor air, and cigarette smoking: evidence from the longitudinal data for young adults. Working Paper No. W6937, National Bureau of Economic Research, February 1999.

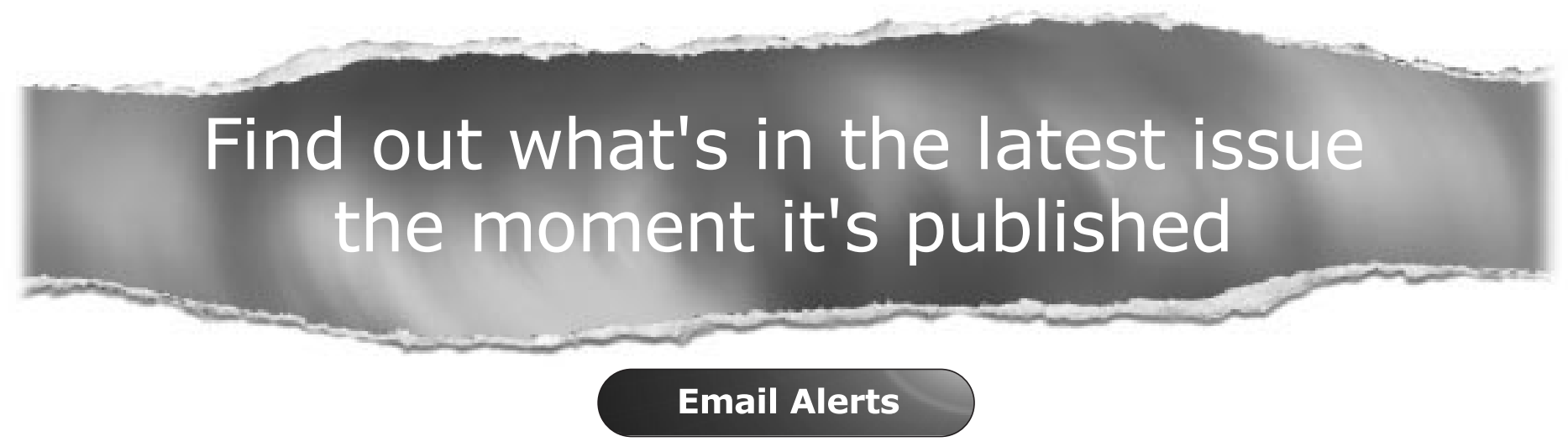

Sign up to receive the table of contents by email every month. You can select from three alerts: Table of Contents (full), TOC Awareness (notice only); Tobacco Control related announcements.

www.tobaccocontrol.com 